\title{
Preferências dos docentes de um curso de Odontologia quanto à forma de visualização de radiografias digitais
}

\author{
Helen Larice Oliveira Moreira*; Marcylene Arruda Braz**; Naiara Leites Larentis*** \\ * Cirurgiã-dentista graduada pela Ulbra Torres \\ ** Acadêmica do curso de Odontologia, Ulbra Torres \\ *** Professora doutora do curso de Odontologia, Ulbra Torres \\ Recebido em 21/08/2016. Aprovado em 02/12/2016.
}

\begin{abstract}
RESUMO
Os egressos de um curso de Odontologia devem estar preparados para responder às demandas da sociedade em todos os segmentos, sendo capazes de incorporar novas tecnologias à sua prática clínica e as interações docente-discente influenciam as escolhas do futuro profissional. Este estudo teve como objetivo avaliar a opinião dos cirurgiões-dentistas docentes de um curso de Odontologia sobre imagens radiográficas digitais e sua preferência entre imagens impressas em filme radiográfico, papel fotográfico ou visualizadas na tela do computador. Os 16 professores com formação em Odontologia avaliaram quatro radiografias interproximais, três periapicais, uma panorâmica e uma telerradiografia de perfil digitais, visualizadas na tela do computador, impressas em filme radiográfico e em papel fotográfico. Após, responderam a um questionário contendo perguntas abertas sobre o assunto. Constatou-se que 6 professores (38\%) preferiram avaliar as imagens na tela do computador, outros 6 (38\%) em filme radiográfico e um professor preferiu avaliar a imagem impressa em papel fotográfico. Um professor relatou não haver diferença na avaliação entre a tela do computador e o filme radiográfico e apenas um relatou não haver diferença entre a visualização na tela do computador e em papel fotográfico. Treze (81\%) profissionais estão habituados a avaliar imagens digitais, enquanto que três (19\%) não estão. Dos dezesseis professores, oito $(50 \%)$ citaram como vantagens das imagens digitais a nitidez, $2(12 \%)$ citaram a possibilidade de ampliação e $6(38 \%)$ citaram diferentes vantagens, como maior chance de acertos, comodidade de manipulação, praticidade, possibilidade de contraste, dispensa de negatoscópio e riqueza de detalhes. Ao final da pesquisa foi possível concluir que os professores do estudo tiveram preferência dividida entre a visualização na tela do computador e em filme radiográfico, utilizam imagens digitais na prática clínica, não tiveram contato com o conteúdo de imagens digitais durante sua formação, mas acreditam que o mesmo deva ser ministrado.
\end{abstract}

Descritores: Radiografia Digital. Diagnóstico. Ensino Odontológico.

\section{INTRODUÇÃO}

Desde a descoberta dos raios $\mathrm{X}$ e a realização da primeira radiografia odontológica, o exame radiográfico se tornou um elemento de fundamental valor para o diagnóstico ${ }^{1,2}$. Os filmes intrabucais e extrabucais convencionais 
permaneceram por muito tempo como as únicas opções de receptores de imagens e, ainda hoje, desempenham um papel relevante nos serviços de saúde, consultórios, clínicas e laboratórios de ensino nos cursos de Odontologia. Contudo, imagens radiográficas convencionais apresentam várias limitações, pois são estáticas, não permitindo manipulações com a finalidade de aperfeiçoar o diagnóstico ${ }^{1}$.

Com a evolução da tecnologia, sistemas radiográficos digitais surgiram visando aprimorar a qualidade da imagem e seu custo, inicialmente bastante alto, vem se tornando cada vez mais acessível ${ }^{3}$. Quando armazenadas no computador, as imagens digitais permitem ajustes de contraste, brilho, ampliação em áreas específicas e inversão da escala de cinza. Também não se deterioram, não envelhecem e não perdem a qualidade com o passar do tempo, além de não sofrerem manchamentos e proliferações fúngicas. Indubitavelmente, dentre todas as suas vantagens, a possibilidade de redução da dose de radiação é a mais expressiva $^{4-16}$.

Existem três diferentes formas para se avaliar uma radiografia digital: na tela do computador, impressa em filme radiográfico ou em papel fotográfico. Porém, estudos apontam que a impressão em papel fotográfico resulta em perda de qualidade das imagens comparativamente à visualização em monitor ${ }^{6,7}$.

Os egressos de um curso de Odontologia devem estar preparados para responder às demandas da sociedade em todos os segmentos, sendo capazes de incorporar novas tecnologias à sua prática clínica ${ }^{17}$. De fato, as Diretrizes Curriculares Nacionais da Odontologia, apresentam em seu artigo $5^{\circ}$ que a formação do cirurgião-dentista tem por objetivo dotar o profissional dos conhecimentos requeridos para o exercício de competências e habilidades específicas, dentre as quais está acompanhar e incorporar inovações tecnológicas no exercício da profissão ${ }^{18}$. Acredita-se que a maioria dos egressos tende a incorporar à sua prática as tecnologias às quais foi exposto durante a graduação $^{19}$. Neste sentido, também nas interações docente-discente ocorre a transmissão, intencional ou não, das crenças, valores, expectativas e atitudes do docente, influenciando as escolhas do futuro profissional ${ }^{20}$.

Assim, o presente estudo teve como objetivo avaliar a opinião dos cirurgiõesdentistas docentes do curso de Odontologia da Universidade Luterana do Brasil (ULBRA), Campus Torres, sobre imagens radiográficas digitais e sua preferência pela avaliação destas imagens impressas em filme radiográfico, impressas em papel fotográfico ou visualizadas na tela do computador.

\section{MATERIAIS E MÉTODOS}

$\mathrm{O}$ presente estudo foi submetido e aprovado por comitê de ética em pesquisa (CAAE n. 06862112.2.0000.5349). Os pacientes realizaram as radiografias por indicação clínica e consentiram no seu uso para a pesquisa. Todos os docentes participantes firmaram Termo de Consentimento Livre e Esclarecido.

Foram utilizadas no estudo quatro radiografias interproximais, três periapicais, uma panorâmica e uma telerradiografia de perfil digitais, obtidas do banco de dados de uma clínica privada de Radiologia em Porto Alegre/RS. As radiografias intrabucais foram adquiridas em um aparelho de raios $\mathrm{X}$ Dabi Atlante $\AA$, com regime de $70 \mathrm{kVp}, 10 \mathrm{~mA}, 0,4$ segundos de exposição e sistema de placa de fósforo Digora Optime ${ }^{\circledR}$. As extrabucais (panorâmica e telerradiografia de perfil) foram obtidas utilizando um aparelho de sensor CCD CRANEX D da marca SOREDEX®, operando em regime de $70 \mathrm{kVp}$. Um radiologista experiente avaliou as imagens, garantindo sua 
qualidade.

As imagens adquiridas foram exportadas em formato JPEG nível 12, o que garante a manutenção de sua qualidade, e então impressas em filme radiográfico Agfa, em impressora Agfa Drystar 5302320 dpi, 4358 x 5232 pixels, e em papel fotográfico fosco em impressora Noritsu QSS-3801 HD, com resolução 640 dpi. Desta forma foram obtidas 27 imagens, 3 de cada radiografia, a fim de constituir três grupos: A) impressas em filme radiográfico; B) impressas em papel fotográfico; e C) no formato digital.

A pesquisa foi realizada no laboratório de radiologia da ULBRA Torres. Para a análise das imagens impressas em filme radiográfico foi disponibilizado o uso de negatoscópio em ambiente escurecido. As imagens impressas em papel fotográfico foram analisadas com a luz artificial acesa. O uso de lupa com aumento de $4 \mathrm{x}$ foi disponibilizado em ambos os casos. Para a análise na tela do computador as imagens foram montadas em uma apresentação, sendo que em cada slide foi apresentada uma das imagens. Para visualização foi utilizado um notebook Dell Inspiron I14 3442-C30, com tela de 14" tipo Led Backlit, display com Truelife e resolução HD 1.366 X 768, em ambiente escurecido, e os avaliadores poderiam aumentar ou diminuir o zoom das imagens como julgassem necessário.

Após analisar as formas de apresentação das radiografias digitais, cada profissional respondeu a opção referente àquela de sua preferência, ou se não existia diferença entre elas.

Imediatamente após avaliar as imagens, os observadores responderam a um questionário contendo perguntas abertas sobre as diferentes formas de avaliação das imagens (quadro 1).

Os dados foram tratados por meio de estatísticas descritivas.

Quadro 1. Instrumento de coleta de dados

Tempo de Formação: ___ anos Especialidade:

1. Explique o porquê da sua escolha entre as três diferentes formas de avaliação de uma imagem digital.

2. Você está habituado a avaliar imagens digitais?

3. Para você quais são as principais vantagens na avaliação de uma imagem digital comparada à convencional?

4. Você normalmente avalia uma imagem digital impressa em papel radiográfico, fotográfico ou na tela do computador?

5. Você aprendeu no curso de graduação a avaliar imagens digitais?

6. Você acha importante que dentro dos cursos de graduação os alunos aprendam a avaliar as imagens digitais? De qual forma? Impressas no filme radiográfico, papel fotográfico ou na tela do computador?

7. Caso você trabalhe com as imagens digitais, você gostaria de receber as imagens em seu local de trabalho via e-mail? Esse e-mail poderia substituir a impressão na imagem? Por quê? 


\section{RESULTADOS}

O corpo docente do curso de Odontologia da ULBRA Torres é constituído por 21 professores, dos quais 17 são cirurgiõesdentistas e todos concordaram em participar da pesquisa. Não houve participação de apenas uma docente, por esta ser coautora do trabalho. A idade dos participantes variou entre 37 e 66 anos, com média de 47,37 $\pm 8,8$. Já o tempo formado variou de 15 a 42 anos, com média de $24,18 \pm 8,85$.

No gráfico 1 estão expostos os resultados obtidos quanto à preferência dos docentes na avaliação das imagens digitais. Houve distribuição equitativa entre visualização na tela do computador e em filme radiográfico.

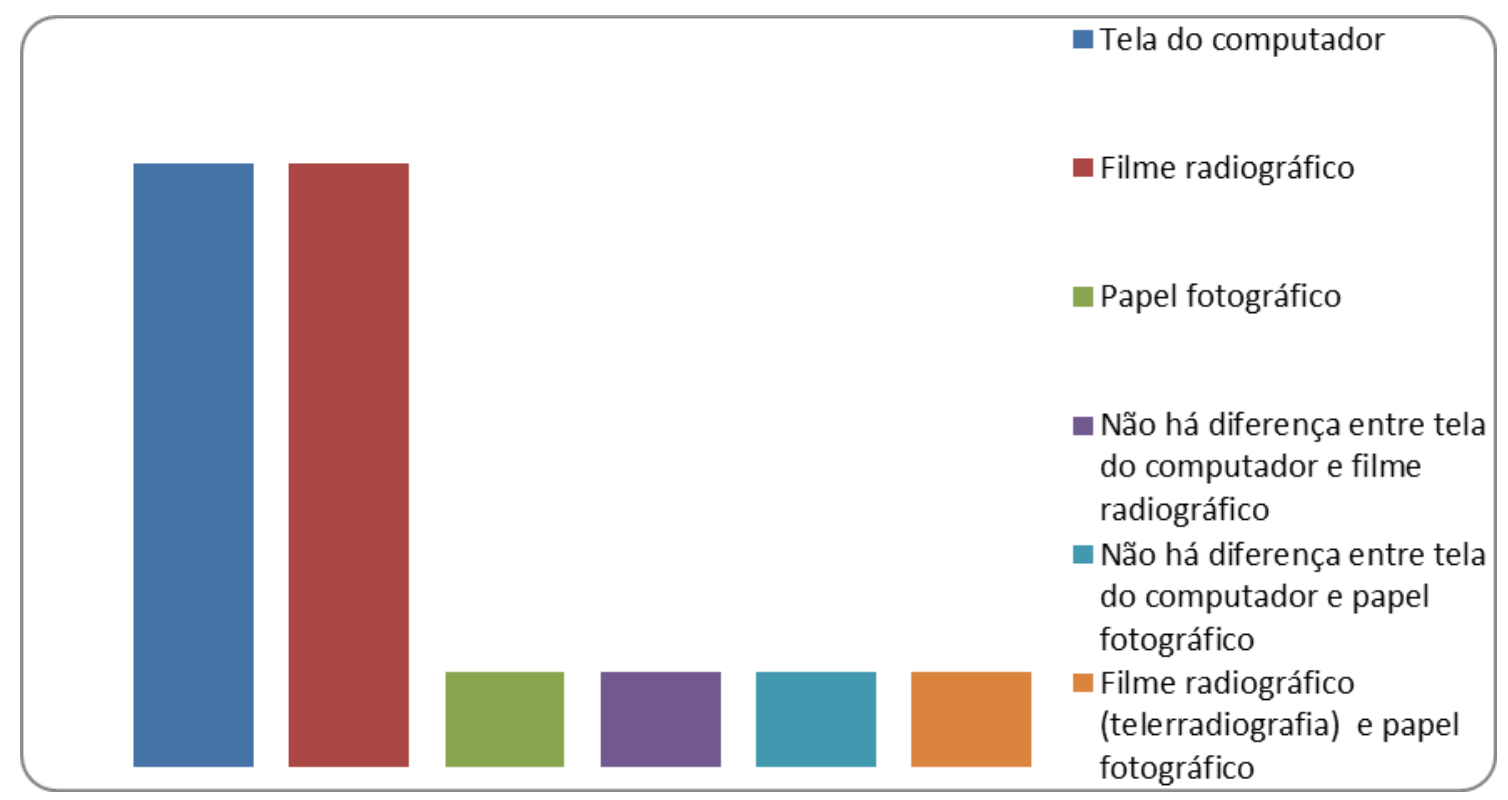

Gráfico 1. Preferência dos docentes quanto à forma de avaliação das imagens digitais $(\mathrm{n}=16)$.

Na tabela 1 pode-se observar a justificativa dos docentes quanto à sua preferência pelo tipo de apresentação de uma imagem digital (pergunta 1). Na pergunta de número 2, quando questionados se estavam habituados a avaliar as imagens digitais, treze $(81 \%)$ professores afirmaram que sim. Todos apontaram vantagens na avaliação de imagens digitais comparadas à convencionais (pergunta 3) e 50\% respondeu nitidez. A possibilidade de ampliação sem o uso de lupa foi citada por $12 \%$ dos participantes. Os outros $38 \%$ dos entrevistados citaram diferentes vantagens, como possibilidade de manipulação e de ajuste de contraste, praticidade, riqueza dos detalhes e dispensa do uso de negatoscópio.

No gráfico 2 estão sumarizadas as respostas dos participantes sobre como eles normalmente avaliam as imagens digitais em seus consultórios (pergunta 4), a maioria impressa em filme radiográfico.

Todos os professores responderam que não utilizaram imagens digitais durante sua formação (pergunta 5), mas a maioria (94\%) considera importante que os alunos de graduação aprendam a avaliar imagens digitais (pergunta 6).

$\mathrm{Na}$ pergunta de número 7 , onde foram questionados se gostariam de receber as imagens digitais por e-mail e se este 
substituiria a impressão, onze professores $(69 \%)$ responderam que gostariam e cinco $(31 \%)$ responderam que não. Dos onze professores que gostariam de receber as imagens digitais por e-mail, oito (50\%) responderam que esse substituiria a impressão e três professores (19\%) responderam que não substituiria.

Tabela 1. Justificativa dos participantes quanto a sua escolha entre analisar as imagens na tela do computador, filme radiográfico ou papel fotográfico.

\begin{tabular}{l|l|c}
\hline Opção & \multicolumn{1}{|c}{ Justificativa } & n (\%) \\
\hline $\begin{array}{l}\text { Visualização na tela do } \\
\text { computador (38\%) }\end{array}$ & $\begin{array}{l}\text { Permite ampliação, dispensa o uso da lupa e do negatoscópio } \\
\text { Praticidade, possibilidade de recursos para trabalhar essa } \\
\text { imagem }\end{array}$ & $2(14 \%)$ \\
& $\begin{array}{l}\text { Recurso de ampliação sem uso de lupa, edição, melhor } \\
\text { armazenamento }\end{array}$ & $1(6 \%)$ \\
Nitidez & $1(6 \%)$ & $1(6 \%)$ \\
& Praticidade & $1(6 \%)$ \\
\hline $\begin{array}{l}\text { Visualização em filme } \\
\text { radiográfico (38\%) }\end{array}$ & $\begin{array}{l}\text { Nitidez } \\
\text { Maior transparência } \\
\text { Qualidade e facilidade de manuseio }\end{array}$ & $2(26 \%)$ \\
\hline $\begin{array}{l}\text { Visualização em papel } \\
\text { fotográfico (6\%) }\end{array}$ & Praticidade, dispensa o uso de negatoscópio & $1(6 \%)$ \\
\hline $\begin{array}{l}\text { Não há diferença entre tela do } \\
\text { computador e filme } \\
\text { radiográfico (38\%) }\end{array}$ & Papel fotográfico se mostrou muito claro & $1(6 \%)$ \\
\hline $\begin{array}{l}\text { Não há diferença entre tela do } \\
\text { computador e papel } \\
\text { fotográfico (38\%) }\end{array}$ & São mais funcionais e dispensam o uso de negatoscópio & $1(6 \%)$ \\
\hline $\begin{array}{l}\text { Telerradiografia de perfil em } \\
\text { filme radiográfico e as outras } \\
\text { imagens em papel fotográfico } \\
\text { (38\%) }\end{array}$ & $\begin{array}{l}\text { Telerradiografia de perfil no filme, porque permite fazer } \\
\text { traçados cefalométricos e as outras em papel fotográfico pela } \\
\text { capacidade de guarda }\end{array}$ & $1(6 \%)$ \\
\hline Total & & $16(100 \%)$ \\
\hline
\end{tabular}

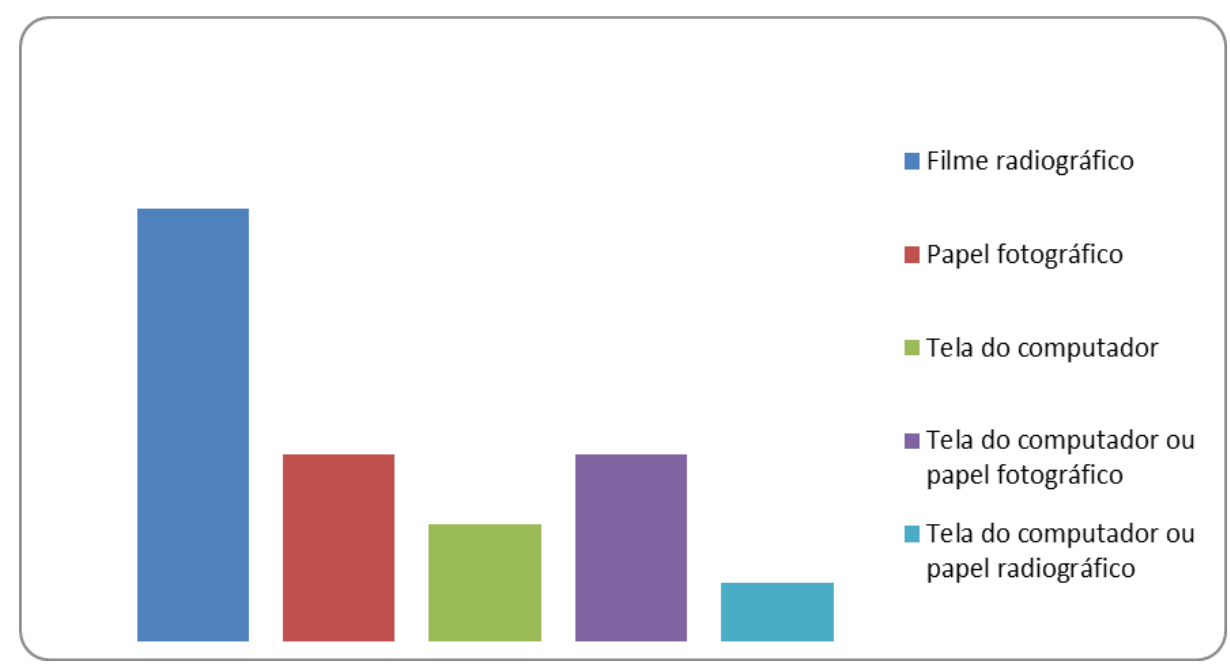

Gráfico 2. Como os professores avaliam as imagens digitais em seus consultórios. 


\section{DISCUSSÃO}

As radiografias digitais estão entre os grandes avanços tecnológicos na Odonto$\operatorname{logia}^{21,22}$. Desde a sua introdução no mercado, os sistemas digitais vêm evoluindo e o seu uso sendo explorado e pesquisado ${ }^{23}$. Para a realização desta pesquisa, o local de escolha foi o laboratório de Radiologia da universidade, devido às condições favoráveis que o mesmo apresenta, tais como luz artificial, negatoscópio e possibilidade de escurecimento do laboratório. Sabe-se que o ambiente escurecido é mais favorável para a avaliação das imagens digitais na tela do computador, assim como a luz artificial acesa favorece a análise das imagens impressas em papel fotográfico. Já para a análise das imagens digitais impressas em filme radiográfico, é fundamental o uso de negatoscópio em ambiente escurecido ${ }^{24}$.

Como a avaliação realizada na tela do computador possibilita a opção de zoom, foi disponibilizado o uso da lupa com 4 aumentos para avaliação das imagens impressas em filme radiográfico e em papel fotográfico, para que todos os métodos de avaliação pudessem ser ampliados e se obtivesse uma padronização.

Esta pesquisa possibilitou a todos os professores cirurgiões-dentistas o contato com as imagens digitais apresentadas nas três diferentes formas, para que pudessem escolher a de sua preferência. Um terço dos professores preferiu avaliar as imagens na tela do computador sob a justificativa da possibilidade de ampliação dessas imagens sem precisar de lupa, além da possibilidade de recursos para se trabalhar imagem, praticidade por dispensar o uso de negatoscópio e facilidade de armazenamento; o que está de acordo com a literatura existente, que ressalta como uma das grandes vantagens das imagens digitais a possibilidade de manipulação dessas imagens: ampliação, contraste, brilho e inversão de tons de cinza, para otimizar o diagnóstico ${ }^{5-7,10,11,15,25,26}$. É importante salientar que todas essas vantagens são perdidas quando as imagens são impressas em filme radiográfico ou em papel fotográfico.

Outro terço dos participantes preferiu avaliar as imagens impressas em filme radiográfico, justificando sua escolha na maior qualidade, nitidez e transparência. Alguns afirmaram que preferem este método de avaliação por estarem mais habituados a avaliarem imagens em filmes radiográficos, já que durante a sua formação não tiveram contato com imagens digitais.

Neste estudo, apenas um professor afirmou que as imagens em papel fotográfico parecem mais claras, o que discorda do estudo feito por Whaites ${ }^{1}$ (2009). Isso porque as imagens digitais impressas em papel fotográfico possuem a qualidade comprometida, já que as impressoras não são capazes de reproduzir as 256 tonalidades de cinza que as imagens digitais apresentam.

Um dos participantes $(6 \%)$ que preferiu avaliar a telerradiografia de perfil impressa em filme radiográfico e as demais radiografias impressas em papel fotográfico justificou a sua preferência na possibilidade de marcação de pontos cefalométricos no filme radiográfico, e na nitidez e a maior capacidade de guarda das imagens em papel fotográfico. Segundo $\mathrm{Mol}^{27}$ (2000), as mensurações digitais facilitam a realização da cefalometria devido à possibilidade de localização automática de marcação de pontos cefalométricos ${ }^{21}$. Por outro lado, Abrahão et al. ${ }^{16}$ (2009), em avaliação qualitativa entre telerradiografia digital e convencional para realização de traçado cefalométrico observaram que não houve diferença estatisticamente significativa quando comparados os dois métodos.

A imagem digital tem provado ser um importante desenvolvimento tecnológico devido 
às incontestáveis vantagens, mas, mesmo com todos estes avanços tecnológicos, alguns profissionais ainda relutam em usufruir esta técnica $^{7,28}$. Neste estudo, acredita-se que a idade e a tempo de formação dos entrevistados foram fatores que influenciaram esta escolha.

A maioria dos participantes gostaria de receber as imagens digitais por e-mail e acham que este pode substituir a impressão, e três acham que não substitui por terem preferência pela imagem impressa no filme, sendo o e-mail somente um acessório a mais, além de não acreditarem na capacidade de guarda e no valor legal dessas imagens.

No Brasil, devido ao grande uso da imagem digital, foram criados meios legais de autenticação dos arquivos através da medida provisória 2200-2 de 24 de agosto de 2001, com poderes para formar a cadeia de certificação digital, ficando instituída a infraestrutura das chaves públicas brasileiras (ICP - Brasil), para garantir a autenticidade, integridade e a validade jurídica de documentos digitais ${ }^{25,29}$.

A presente pesquisa obteve resultados diferentes do trabalho feito por Segalla (2011). Essa divergência nos resultados pode ser explicada por hoje os profissionais estarem um pouco mais habituados a avaliar as imagens na tela do computador, devido ao avanço da tecnologia e também ao conhecimento destes avanços por parte dos profissionais, bem como as vantagens que este método de avaliação proporciona, como contraste, ampliação, brilho e zoom, além de preservarem o meio ambiente. Muitas destas vantagens são perdidas quando a imagem é impressa tanto no filme radiográfico como no papel fotográfico.

A radiografia digital vem ocupando uma posição de destaque na Odontologia, ampliando a sua utilização e superando suas limitações, substituindo a radiografia convencional. Assim, torna-se necessário que o profissional conheça seus benefícios para que possa usufruir de forma correta e este método venha a potencializar o diagnóstico por imagem. Por isso, é importante que os cursos de Odontologia apresentem este conteúdo, uma vez que são formadores de opinião e determinantes de condutas futuras.

\section{CONCLUSÃO}

A partir dos resultados obtido foi possível concluir que a maioria dos professores dividiu a sua preferência entre a avaliação de imagens digitais na tela do computador e impressas no filme radiográfico, que estes profissionais utilizam imagens digitais na prática clínica, que não tiveram contato com este conteúdo durante sua formação, mas acreditam que o mesmo deva ser ministrado na graduação.

\section{ABSTRACT \\ Preferences among teachers in a Dental school regarding the way for digital radiographic visualization}

Dental School's graduates must be prepared to respond to the demands of society in all segments, being able to incorporate new technologies into their clinical practice. Teacher-student interactions influence the choices of the professional future. The aim of this study was to evaluate the opinion of dentists teaching dentistry on digital radiographic images and their preference among images printed on radiographic film, photographic paper or visualized on the computer screen. The 16 professors of a Dental School who have Dentistry degree evaluated four interproximal radiographs, three periapical, one panoramic and one digital lateral teleradiography visualized on the computer screen, printed on radiographic film and on photographic paper. Afterward, they answered a questionnaire containing open questions about the subject. It was found that $38 \%$ of teachers preferred to evaluate the images on the computer screen, another $38 \%$ preferred the images printed on $\mathrm{X}$ ray film and one teacher preferred the image 
printed on photographic paper. One teacher reported no difference between the computer screen and radiographic film. Only one teacher reported that there was no difference between viewing on the computer screen and on photographic paper. Thirteen $(81 \%)$ are used for evaluating digital images, while three (19\%) are not. Of the sixteen teachers, eight (50\%) cited the advantages of digital images as sharpness, 2 (12\%) cited the possibility of magnification and $6(38 \%)$ cited different advantages, such as greater chance of correctness, ease of manipulation, Possibility of contrast, dispensing of light box and richness of details. It was possible to conclude that the teachers of the study had a divided preference between the computer screen and x-ray film, use digital images in clinical practice, did not have this subject at graduation and believe that it should be taught.

Descriptors: Digital Radiography. Diagnosis. Dental Education.

\section{REFERÊNCIAS:}

1. Whaites E. Princípios de radiologia Odontológica. 4 ed. Rio de Janeiro: Elsevier; 2009.

2. Silva, WR. Sistemas de imagens digitais com aplicabilidade na Odontologia [Monografia] Porto Alegre: Universidade Federal do Rio Grande do Sul; 2011.

3. Castilho JCM, Moraes LC, Moraes MEL, David SMN, Dotto PP. Radiografia digital: conceitos básicos. Rev Espelho Clínico. 2004;43:7-9.

4. Panella J. Radiologia odontológica e imaginologia, Rio de Janeiro: Guanabara Koogan, 2006.

5. Kreich EM, Leal GA, Slusarz PAA, Santini RM. Imagem digital na Odontologia. Publ UEPG Ci Biol Saúde. 2005;11:53-61.

6. Cruz GA, Moraes LC, Médice Filho E, Castilho JCM. Utilização de radiografia digital em Odontologia. Rev ABO Nac. 2004;12(5):283-7.

7. Castilho JCM, Moraes LC. Costa NP, Dotto GN. Radiografia digital - histórico e evolução. Rev Odonto Ciênc. 2003; 18(41)
:279-84.

8. Haiter Neto F, Melo DP. Radiologia digital. Rev ABRO. 2010;11(1):5-17.

9. Moraes JEP, Mahl CRW. Documentação digital em imaginologia. Odontol Clín Cient. 2004;3(3):173-9.

10. Duarte HEM, Araújo CCM, Sannomiya EK. Sistemas digitais na Radiologia dentomaxilo-facial: uma nova fase na Odontologia? Rev Bras Odontol. 2008; 65(1) :42-7.

11. Braga EFA, Silva PG, Vardasca de Oliveira PT, Ferrão Júnior JP, Marques J. Comparação das imagens radiográficas digitais e convencionais em reabsorções ósseas periodontais. Pesq Bras Odontoped Clin Integr. 2011;11(4):585- 91.

12. Abreu MV, Araújo AA, Ferreira EF, Haiter Neto F Estágio atual da radiografia digital. Rev ABRO. 2000,1(1):1-6.

13. Candeeiro GTM, Bringel ASF, Vale IS. Radiologia digital: Revisão de Literatura. Rev Odontol Araçatuba. 2009;30(2):38-44.

14. Casanova MLS, Haiter Neto F, Oliveira AEF. Avaliação da qualidade das imagens digitais panorâmicas adquiridas com diferentes resoluções. Pós-Grad Rev Odontol. 2002;5(2):23-8.

15. Botelho TL, Mendonça EF, Cardoso LLM. Contribuição da radiologia digital na clínica odontológica. ROBRAC. 2003;12(33):55-9.

16. Abrahão TSM, Goldenberg FC, Tacola CG, Sannomya EK. Avaliação qualitativa entre radiografias cefalométricas laterais digital e convencional. R Dental Press Ortodon Ortop Facial. 2009;14(3):60-8.

17. Brownstein SA, Murad A, Hunt RJ. Implementation of new technologies in U.S. Dental School curricula. J Dent Educ. 2015;79(3):259-64.

18. BRASIL. Resolução $n^{\circ}$ 03/2002 de 19 de fevereiro de 2002. Dispõe sobre as Diretrizes Curriculares Nacionais dos cursos de graduação em odontologia. Diário Oficial da União 2002. (Acesso em 18 nov. 2016). Disponível em: http://portal.mec.gov.br/cne/ arquivos/pdf/CES032002.pdf.

19. Iacopino A. The influence of "new science" 
on dental education: current concepts, trends, and models for the future. J Dent Educ. 2007;71(4):450-22.

20. Lima TV. O impacto das atitudes na educação de alto desempenho. (Acesso em 18 nov. 2016). Disponível em http://www.linhadireta.com.br/publico/image s/pilares/fozr6xvhtxqw.pdf

21. Rosenfeld AL. Digital technology: dentistry must not overlook the big picture. Compend Contin Educ Dent. 2014;35(10):778-9.

22. DiVito R. Getting Ahead: "Real-World" Technologies Give Dental School Grads an Edge. Compend Contin Educ Dent. 2014;35(10):788.

23. Hehn L, Mahl CRW, Freitas MPM, Conde A, Veeck EB, Fontanella V. Comparação de três sistemas digitais em relação à densidade óptica de cimentos de ionômero de vidro. Rev Odonto Ciênc. 2007;22(57):233-7.

24. Segala LC. Análise da preferência dos professores cirurgiões dentistas da ULBRA Torres entre radiografias interproximais impressas em filme radiográfico, papel fotográfico e na tela do computador [Monografia] Torres: Universidade Luterana do Brasil; 2012.
25. Brunieri LS, Tanaka EE, Ito FA. Proteção da integridade e da autenticidade das radiografias odontológicas digitais. Odontol Clín Cient. 2011;10(3):211-6.

26. Vidigal BCL, Silveira OS, Francio LA, Manzi FR. Aplicação da radiografia digital na Odontopediatria. Arqu Bras Odontol. 2010; 6(3):170-8.

27. Mol A. Image processing tools for dental applications. Dent Clin North Am. 2000; 44(2):299-318.

28. Borges AFS, Sanabe ME, Basso MD, SantosPinto L. Acurácia das medidas de limas endodônticas em radiografia digital e convencional - estudo in vitro em dentes decíduos. RFO UPF. 2010;15(1):25-9.

29. Brasil. Medida Provisória 2200-2 de 24 de agosto de 2001. Institui a Infra- Estrutura de Chaves Públicas Brasileira - ICP Brasil. Brasília, 24 de agosto de 2001. (Acesso em 7 dez. 2015). Disponível em: http://www. planalto.gov.br.

Correspondência para:

Marcylene Arruda Braz

e-mail: marcy.braz@hotmail.com

Oswaldo Aranha, 651

95560-000 Torres-RS. 